\title{
SUMMER SCHOOL OF COLUMBIA UNIVERSITY
}

As in the two years past, the summer courses at Columbia Uni versity, New York City, include three sets of lectures of interest to all nurses, which would be most profitable to anyone unable to give time for a long course of study yet anxious to extend her knowledge on certain subjects. The courses in chemistry are of interest to anyone studying foods and food values, and the artificial feeding of babies; those on domestic science cover most of this attractive field; those on physical education broaden and extend the teachings of our training-schools in physiology and anatomy.

The following extracts are from the annual announcement, which will be sent on application. Any nurse who could arrange to attend these or other lectures of the Summer School during July and August, 1906, would be well repaid for her time and expense by the education gained in any subjects she selected for study:

\section{COLUMBIA UNIVERSITY, SUMMER SESSION, 1906}

The seventh Summer Session of Columbia University will open on Thursday July 5, 1906, and continue until Thursday, August 16, inclusive. No stated exercises are held on Saturday, although in some cases laboratories will be open on that day.

Each course will consist of a minimum of 30 lectures or other exercises, or their equivalent in laboratory or field work.

$\cos \mathrm{T}$

1-Registration or matriculation fee (payable but once) $\ldots \ldots \ldots \ldots \ldots 5.00$

2-Tuition fee (for any course or courses aggregating not

more than 6 points, but see p. 14 of catalogue) .... .......\$30.00

It is believed that the total expense involved in attendance upon the Summer Session, including tuition fee, but excluding railroad fare, may readily be kept below $\$ 95$. In no event need it exceed $\$ 110$.

\section{ACCOMMODATIONB}

A University residence located at 1230 Amsterdam avenue, between one hundred and twentieth and one hundred and twenty-first streets, will be open for the accommodation of the women students of the Summer Session.

A special rate of $\$ 50$ is made for the students of the Summer Session, from dinner on Wednesday, July 4, to breakfast on Friday, August 17, inclusive. This rate is payable in advance, and includes room, board, and for residents of Whittier Hall, laundry (one dozen plain pieces per week).

\section{CHEMIBTRY}

s13a-Proximate organic and sanitary analysis. Conferences and laboratory work, 15 to 30 hours a week. Professor Sherman.

The work in this course may be selected, according to the time and needs of 
the student, from among the following subjects: the quantitative analysis of foode and the physiological products; artificial digestion experiments; the preparation and analysis of modified milk; the determination of heat of combustion by the bomb calorimeter; any of the organic or sanitary analyses included in Course 13 (see Announcement of the Division of Chemistry).

$\mathrm{sF}$-Chemistry of nutrition. 5 hours lectures and collateral reading, 1 point Professor Sherman.

This course prerequires a knowledge of elementary organic chemistry and deals mainly with the functions of the proteids, fats, and carbohydrates in nutrition and the analytical and experimental methods by which the quantitative composition and nutritive values of food are determined. It includes a critical study of the methods and results of recent investigations in food chemistry and human nutrition.

This course may be taken with s13a, with s20, or any of the courses in Domestic Science given at Teachers College.

s30-Organic chemistry laboratory course. 1 point. Dr. Beans.

This course is a study of the typical reactions of organic compounds with special reference to the relations existing between them. Among the compounds prepared are the following: chloroform, ether, urea, nitrobenzene, anilin, salicylic acid, methyl orange, fluorescein, quinolin, etc.

The laboratory work can be varied, depending on the time and needs of the student, the maximum being thirty hours per week.

\section{DOMESTIC BCIENCE}

sl-Foods. Lectures, laboratory work, essays, and collateral reading; 4 points. Miss Benton. Laboratory fee, \$5.

This course covers the following general topics: The composition and nutritive value of foods; fundamental principles and processes of cookery; comparative study of fuels and cooking apparatus; marketing. It is designed to give a thorough knowledge of theory and practice in cooking and to aid the student in arranging subject-matter for teaching. Special attention is given to scientific methods of laboratory work, and to the adaptation of such methods to the school.

This course will be continued in the Summer Session of 1907.

s3-Food production and manufacture. Lectures, reading, and excursions; 2 points. Professor Vulte.

This course covers the following special topics: cereals, preparation of meals, flours and patented products; composition and use of leavening agents; bread, biscuit, and pastry; treatment of vegetables and fruits; jellies and preserves; oils and fatty bodies; water for drinking and detergent use, including mineral waters and non-alcoholic beverages.

This course will be continued in the Summer Session of 1907.

85-Household chemistry. Lectures, reading, and laboratory work; 3 points. Professor Vulte.

This is a course of instruction designed to present a study of the more important food principles, including sugars, starches, proteids, fats, mineral salts, special attention being given to the changes taking place during domestic manipulation and digestion; examination of water for domestic purposes.

Students are recommended to take the lectures in Chemistry sF as supplementary to this course. 
Students who have had the equivalent of this course will be given the opportunity to pursue advanced studies in the chemistry of foods and stimulants in the laboratory

Laboratory fee, $\$ 5$.

This course will be continued in the Summer Session of 1907.

89-Household mechanics and sanitation. Lectures, conferences, and collateral reading; 2 points. Professor Vulte.

This course includes discussion of the following topics: The situation, plan, and construction of the city and country dwelling; the relative cost of various types; design and care of the systems of plumbing, lighting, beating, and ventilation; interior and exterior decoration.

This course will be continued in the Summer Session of 1907.

\section{PRYSICAL EDUCATION}

687-Personal hygiene and first aid to the injured. Lectures and practical work; 2 points. Professor Meylan.

This course considers personal health as a problem in vital economics; the human body as an organic machine, and the aim of personal hygiene to be the provision of the most efficient body mechanism for the life-needs of the individual. The topics include the argument for the careful study of health and hygiene; ideals of health influencing different peoples; structure and functions of the human body; changes in the organism due to evolution and civilization and the health problems arising from these changes; conditions necessary to the perfect state of the body and the activity of the various functions; causes of weakness, injury, degeneration, and disease; improvement of health and prevention of disease by hygienic means; methods of first aid to the injured.

s108-Anthropometry, diagnosis, and prescription of corrective exercises. Lectures and practical work; 2 points. Professor Meylan.

This course deals with the practical methods of studying the human organism; of determining its conditions and needs, and of applying the various measures indicated for normal development, improvement of health and strength, correction of deformities, prevention and cure of certain forms of disease. This course includes the following: Recording of personal and family history; measuring and testing the body; observation of organic conditions and physical signs; theory and tabulation of statistics; use of graphic methods for representing bodily conditions and changes; individual prescription of exercise and hygienic regimen, corrective exercise for common deformities, such as round shoulders and spinal curvature; adaptation of movements for functional disorders and special nervous conditions. There will be practical work for all students. 